\section{OAK RIDGE NATIONAL LABORATORY}

MANAGED BY UT-BATTELLE

FOR THE DEPARTMENT OF ENERGY

\author{
CRADA Final Report \\ for
}

CRADA NumberORNL99-0559

\section{EPILEPTIC SEIZURE FOREWARNING \\ BY NONLINEAR TECHNIQUES}

\author{
L. M. Hively \\ V. A. Protopopescu \\ Oak Ridge National Laboratory \\ J. Joseph \\ VIASYS Healthcare Inc. \\ Prepared by the \\ Oak Ridge National Laboratory \\ Oak Ridge, Tennessee 37831 \\ managed by \\ UT-Battelle, LLC \\ for the \\ U.S. Department of Energy \\ Under contract DE-AC05-00OR22725
}

FOR PUBLIC RELEASE 


\section{DOCUMENT AVAILABILITY}

Reports produced after January 1; 1996, are generally available free via the U.S. Department of Energy (DOE) Information Bridge.

Web site http://www.osti.gov/bridge

Reports produced before January 1,1996, may be purchased by members of the public from the following source.

National Technical Information Service

5285 Port Royal Road

Springfield, VA 22161

Telephone 703-605-6000 (I-800-553-6847)

TDD 703-487-4639

Fax 703-605-6900

E-mail info@ntis.fedworid.gov

Web site http://www.ntis.gov/support/ordernowabout.htm

Reports are available to DOE employees, DOE contractors, Energy Technology Data Exchange (ETDE) representatives, and International Nuclear Information System (INIS) representatives from the following source.

Office of Scientific and Technical Information

P.O. Box 62

Oak Ridge, TN 37831

Telephone 865-576-8401

Fax 865-576-5728

E-mail reports@adonis.osti.gov

Web site http://www.osti.gov/contact.html 
CRADA Final Report

for

CRADA Number ORNL99-0559

\title{
EPILEPTIC SEIZURE FOREWARNING BY NONLINEAR TECHNIQUES
}

\author{
L. M. Hively \\ V. A. Protopopescu \\ Oak Ridge National Laboratory \\ J. Joseph \\ VIASYS Healthcare Inc. \\ under \\ CRADA No. ORNL 99-0559 \\ between \\ Oak Ridge National Laboratory (ORNL) \\ and \\ Nicolet Biomedical Inc. (NBI) \\ Madison, Wisconsin \\ Date Published: January 2002 \\ FOR PUBLIC RELEASE \\ Prepared by \\ OAK RIDGE NATIONAL LABORATORY \\ Oak Ridge, Tennessee 3783 1-6285 \\ managed by \\ UT-BATTELLE, LLC \\ for the \\ U.S. DEPARTMENT OF ENERGY \\ under contract DE-AC05-00OR22725
}





\section{CONTENTS}

Page

ABSTRACT

v

1. INTRODUCTION.

2. BACKGROUND

1

3. CRADA OBJECTIVES

2

4. BENEFITS TO DOE/LTR PROGRAM ….................................................................

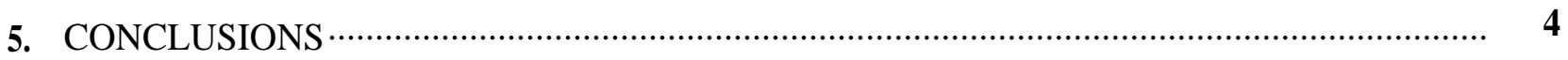

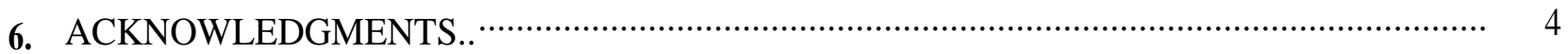

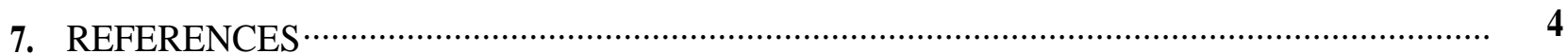

APPENDIX A: TASKS FROM DECEMBER 2000 EXTENSION OF CRADA............................ A-1

APPENDIXB: TASKS FROM JULY 2001 EXTENSION OF CRADA...................................... B-1

APPENDIXC: CHARACTERIZATION OF TEMPORAL LOBE EPILEPSY DATASETS . . . . . . . . . C-1

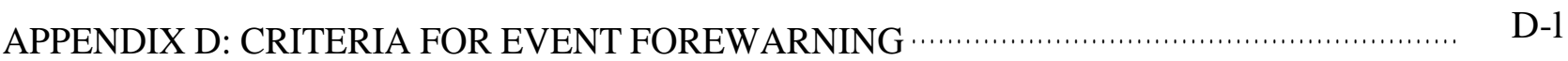

APPDNEIX E: SUMMARY OF FOREWARNING ANALYSIS $\ldots \ldots \ldots \ldots \ldots \ldots \ldots \ldots \ldots \ldots \ldots \ldots \ldots \ldots \ldots \ldots \ldots$

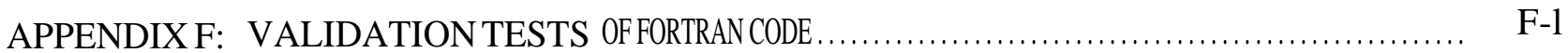

APPENDIX G: ANALYSIS TO RESOLVE CHANNEL INCONSISTENCY ….......................... G-1

APPENDIX H: FUTURE WORK FOR AN AMBULATORY PROTOTYPE ….......................... H-1 


\begin{abstract}
This report describes work that was performed under a Cooperative Research and Development Agreement (CRADA) between UT-Battelle, LLC (Contractor) and a commercial participant, VIASYS Healthcare Inc. (formerly Nicolet Biomedical, Inc.). The Contractor has patented technology that forewarns of impending epileptic events via scalp electroencephalograph (EEG) data and successfully demonstrated this technology on 20 datasets from the Participant under pre-CRADA effort. This CRADA sought to bridge the gap between the Contractor's existing research-class software and a prototype medical device for subsequent commercialization by the Participant. The objectives of this CRADA were (1) development of a combination of existing computer hardware and Contractor-patented software into a clinical process for warning of impending epileptic events in human patients, and (2) validation of the epilepsy warning methodology. This work modified the ORNL research-class FORTRAN for forewarning to run under a graphical user interface (GUI). The GUI-FORTRAN software subsequently was installed on desktop computers at five epilepsymonitoring units. The forewarning prototypes have run for more than one year without any hardware or software failures. This work also reported extensive analysis of model and EEG datasets to demonstrate the usefulness of the methodology. However, the Participant recently chose to stop work on the CRADA, due to a change in business priorities. Much work remains to convert the technology into a commercial clinical or ambulatory device for patient use, as discussed in App. $\mathrm{H}$.
\end{abstract}





\section{INTRODUCTION}

Epilepsy from all causes affects nearly three million. U.S.. victims, with 125,000 new cases annually. An epileptic seizure can cause muscle tremors, unconsciousness, loud vocalization, and uncontrolled bladder/bowel function. Drug therapy may frequently cause worse side effects than the uncontrolled seizure itself, such as drowsiness, poor memory, lack of coordination, disorientation, and impaired thinking. Moreover, 25-30\% of epileptic patients are unresponsive to anti-seizure drugs.

Severe seizures may lead to sudden death due to accidents, breathing interruption, and cardiac failure. This threat is particularly serious for patients who cannot make their needs known such as adults with other disabilities and small children. Continuous clinical or hospital monitoring of such patients is very expensive. Home monitoring is much less expensive and requires a wall-powered monitor, thus severely restricting patient mobility, Therefore, reliable ambulatory warning is needed to facilitate data review, diagnosis, and prompt medical care.

\section{BACKGROUND}

Researchers at Oak Ridge National Laboratory (ORNL) have developed techniques for diagnosis of nonlinear processes. The ORNL team analyzed scalp EEG data via conventional nonlinear methods under. the sponsorship of the ORNL Laboratory-Directed Research and Development program in 1994-1995. That work found inconsistent detection and forewarning capability in mutual information, correlation dimension, and Kolmogorov entropy of scalp EEG.' Three U.S. patents arose from that effort. Scalp EEG includes electrical artifacts from eye blinks and other muscular activity, which are removed. with a novel zero-phase quadratic filter while preserving the nonlinear. amplitude and phase relationships [U.S. Patent \#5,626,145 (ref. 2)]. Nonlinear analysis of this artifact-filtered data then detects [U.S. Patent $\# 5,743,860$ (ref. 3)] and predicts [U.S. Patent \#5,857,978 (ref. 4)] epileptic seizures from one channel of scalp EEG. Application of these same methods to other data showed that better techniques were needed for detecting a change in condition, such as forewarning of failure in electrical machines arid' cardiac fibrillation from electrocardiogram data. Subsequent research in 1995-1997 (ref. 5) developed a new nonlinear method for detection of condition change using a discretized phase-space (PS) analysis after artifact filtering. This approach was later patented [US. Patent \#5,815,413 (ref. 6)]. Details of this method with applications to epilepsy forewarning were presented recently at technical conferences ${ }^{7-9}$ and published as a peer-reviewed paper." Patent-pending improvements" have been added to the methodology. The forewarning methodology is presently implemented as research-class FORTRAN that runs on a desktop computer.

On February 16, 1999, Dr. Jon Joseph of VIASYS contacted Dr. Lee Hively of ORNL about collaboration to commercialize the seizure forewarning technology. Dr. Joseph met with ORNL staff on April 12, 1999, and asked ORNL to demonstrate the technology 'on VIASYS data. Dr. Joseph and Leah Hanson (VIASYS) met with ORNL staff again on August 30, 1999, to discuss the results of ORNL's analysis of 20 datasets. Based on the successful outcome of this demonstration, VIASYS decided to pursue collaboration with ORNL under a CRADA, which began October 1, 1999. A peer-reviewed paper in the journal Chaos $^{12}$ described the results of this pre-CRADA analysis, as part of FYOO effort under this CRADA. An invited review paper ${ }^{13}$ was published in the Clinical Journal Of Neurophysiology describing FY01 work under this CRADA. ${ }^{14}$ Appendixes A-B of this. report show the specific tasks from the December 2000 and July 2001 extensions of the CRADA, respectively. This report documents the CRADA activity since the last annual report" and is the final report of the CRADA. 
A narrative of the recent CRADA work follows. Late September 2000, the Participant completed delivery of 213 multichannel EEG datasets and their characterizations to ORNL. Results of ORNL's extensive analysis of those data were presented to Dr. Jon Joseph and Ms. Char Merican during a review meeting on November 20, 2000. That initial analysis showed a combined rate of $52 \%$ for true positives plus true negatives, based on a judicious choice of EEG channels for forewarning. Subsequent analysis by Dr. Thomas Cook (biostatistician at the University of Wisconsin in Madison) found that no consistent channel provided forewarning of epileptic events across multiple datasets from the same patient. Consequently, Dr. Joseph decided that an insufficient basis existed to pursue a commercial forewarning device immediately, but that further analysis was needed. In December 2000, the Participant and ORNL extended the CRADA effort to June 30, 2000; see App. A. The Participant provided $\$ 100 \mathrm{~K}$ of additional funds-in for that work. The Participant provided changes to the dataset characterizations as new information was received from the collaborating physicians. ORNL also performed new analyses on model data to validate the forewarning technology.

The Participant's staff (Dr. Jon Joseph and Ms. Char Merican) met with the Contractor's team on March 26, 2001 to review the Q1/CY01 work. That review showed that the Contractor's method provided 1-60 min of forewarning in 46 of 50 temporal lobe event datasets and no indications in all 12 normal datasets. The Contractor's analysis showed consistency and robustness of the PS dissimilarity measures for both model and EEG data. The Contractor's analysis also demonstrated the importance of the cutset length for both model and EEG data vs the intrinsic time scales. Detailed EEG analysis revealed forewarning for three successive events in one dataset, the first such demonstration with our approach. The choice of PS and threshold parameters for robust forewarning was based on extensive retrospective analysis. The review also revealed several important inconsistencies. First, the channels were not consistent for true positives (event forewarning with a real event) and true negatives (no forewarning when no event occurs) across multiple datasets from the same patient (11 such patients). Second, the method gave forewarning of multiple events in only one of the six datasets with such multiple events. Moreover, the "best" parameter set did not show the multiple forewarnings in that one dataset. Third, the channels with event forewarning were not consistent with the "active lead" corresponding to the electrode with the first clinical indication of the event. This analysis was performed on clinically controlled data with 'carefully chosen PS parameters, in sharp contrast to the poorly controlled conditions for a real clinical (or later ambulatory) device. Weighing the positive forewarning results against these inconsistencies, Dr. Joseph expressed lack of sufficient confidence for converting the Contractor's technology to a clinical forewarning device immediately. The July 2001 revision of the CRADA (App. B) added several tasks to address these inconsistencies and extended the CRADA to December 31,2002. On August 26, 2001, Dr. Jon Joseph requested that ORNL stop work on the CRADA due to a change in business priorities of their company, now VIASYS Healthcare Inc. (formerly Nicolet Biomedical Inc.). Prior to the CRADA termination notice, the Participant had provided an additional $\$ 50 \mathrm{~K}$, which funded completion of the work in progress and preparation of this final CRADA report.

\section{CRADA OBJECTIVES}

Work under this CRADA sought to develop a combination of existing computer hardware and ORNL-patented software into a clinical process for warning of impending epileptic events in human patients. This effort was the first step in bridging the gap between ORNL's existing research-class software and commercialization of a prototype medical device. Specific technical goals included (1) validation of the scientific basis for the epilepsy forewarning methodology, and (2) development of a combination of existing computer hardware and Contractor-patented software into a clinical process for forewarning of epileptic events. The second goal, involved three objectives: (a) software to analyze 
real-time scalp EEG data for pre-seizure indications, (b) a user interface between the.QRNL software and existing commercial software, and (c) improvements in the forewarning methodology.

In fulfillment of CRADA Task 1.1 (App. A), the Participant provided 213 EEG datasets [more than 65 Gigabytes (GB)]. The Participant also provided detailed characterizations of the datasets, with subsequent improvements as they were received from the attending physicians. Appendix $C$ summarizes the characterizations for the 41 temporal lobe epileptic datasets and 20 normal (non-seizure) datasets.

In fulfillment of CRADA Task 1.2 (App. A), ORNL analyzed 61 datasets, which the Participant chose as a "homogeneous" set. An invited review paper ${ }^{13}$ has been published in the Journal of Clinical Neurophysiology, which documents the results of this FY01 analysis. Appendix D describes criteria for forewarning of an epileptic event. Appendix E summarizes the results ${ }^{13}$ for each dataset with very solid, robust forewarning that outperforms state-of-the-art algorithms for seizure detection alone.

In fulfillment of CRADA Task 1.3 (App. A), ORNL has continued to improve the methodology. ORNL performed extensive tests on the FORTRAN implementation. Appendix F describes validation tests of the FORTRAN code. The detailed analyses of model and EEG data are described in ref. 13.

In fulfillment of Task 2 (App. A), the Contractor and Participant jointly specified the hardware and software requirements for a prototype device (Task 2.1). The Participant developed a GUI on a desktop computer (Task 2.2). The Contractor modified the, research-class FORTRAN to receive data from the GUI and to provide forewarning results to, the GUI (Task 2.3). The Participant installed and validated the combined GUI-FORTRAN software with support from the Contractor (Tasks 2.4-2.5). Reference 15 describes details of this work.

In fulfillment of Task 3 (App. A), the Participant cloned the prototype hardware and software from Task 2. The Participant completed installation of the prototype clones in epilepsy monitoring units at five different clinical sites on June 30, 2000. These prototypes have run continuously for more than one year without any hardware or software failures.

In fulfillment of Task 4.1 (App. B), ORNL contacted Dr. Brian Litt, M.D. (University of Pennsylvania). Dr. Litt and collaborators in Bonn, Germany, were planning an invitation-only epilepsy prediction workshop (end of October 2001) to which ORNL was invited. The -events of September 11, 2001 caused postponement of the workshop, which will probably be rescheduled during 2002.

In fulfillment of Task 4.2 (App. B), ORNL began (but did not complete) analysis of epileptic and normal datasets to resolve the channel inconsistency issue; see App. G for further details. ORNL has not pursued work on Tasks 4.3-4.7 (App. B) due to the Participant's decision to terminate the CRADA.

\section{BENEFITS TO DOE/LTR PROGRAM}

This work benefits the Participant, the Contractor, and the DOE/LTR mission of converting laboratory developments into commercializable. technology. In particular, the first goal (validation of the scientific basis for the epilepsy forewarning methodology) was met by ref. 13, which describes the scientific methodology for forewarning of epileptic events based on the. analysis under Task 1.2 above. The FY 2000 CRADA report" describes completion of the second goal, in terms of design and implementation. of computer hardware and. Contractor-patented software into a clinical process and apparatus for forewarning of epileptic events. These prototype units were installed at five different clinical sites by VIASYS in April-June 2000. As of this writing, all of the prototype units have been running for over one year without any hardware or software failures, which fulfills objectives $2 a-2 b$ above. Finally, ORNL improved the forewarning methodology (97\% trues) in fulfillment of objective 2c. Appendixes C-G provide details of the work performed. 


\section{CONCLUSIONS}

Work under CRADA \#ORNL99-0559 was performed on schedule and within budget. Oak Ridge National Laboratory made one invention disclosure during this work. On July 3 1, 2001, VIASYS Healthcare, Inc. extended the CRADA through December 31 , 2002, but subsequently informed ORNL on August 26, 2001 of its decision to stop collaboration and licensing of the technology due to a change in business priorities. Appendix $\mathrm{H}$ explains the additional work to demonstrate a viable device to forewarn of epileptic events.

\section{ACKNOWLEDGEMENTS}

The ORNL work was sponsored in part by the U. S. Department of Energy, Office of Science, under the Laboratory Technology Research Program. The work was performed as part of a CRADA between ORNL and VIASYS Healthcare, Inc.

\section{REFERENCES}

1. L. M. Hively, N. E. Clapp, C. S. Daw, and W. F. Lawkins, Nonlinear Analysis of EEG for Epileptic Seizures, ORNL/TM- 1296 1, Oak Ridge National Laboratory, Oak Ridge, TN, April 1995.

2. N. E. Clapp and L. M. Hively, Method and Apparatus for Extraction of Low-Frequency Artifacts from Brain Waves for Alertness Detection, U.S. Patent \#5,626,145, May 6, 1997.

3. L. M. Hively, N. E. Clapp, C. S. Daw, and W. F. Lawkins, Apparatus and Method for Epileptic Seizure Detection using Nonlinear Techniques, U.S. Patent \#5,743,860, April 28, 1998.

4. L. M. Hively, N. E. Clapp, C. S. Daw, and W. F. Lawkins, Epileptic Seizure Prediction by Nonlinear Methods, U.S. Patent \#5,857,978, January 12, 1999.

5. L. M. Hively, "Data-Driven Nonlinear Technique for Condition Monitoring," proceedings of the Maintenance and Reliability Conference, Vol. 1, pp. 16.01-1 6.10, Knoxville, TN (1997).

6. L. M. Hively and E. G. Ng, Integrated Method for Chaotic Time Series Analysis, U.S. Patent \#5,8 15,413, September 29, 1998.

7. P. C. Gailey, L. M. Hively, and V. A. Protopopescu, "Detection of Condition Change in Nonlinear Times Series Using a Connected-Phase-Space PDF," proceedings of the Am. Phys. Soc., paper LC32.06, March 23, 1999.

8. L. M. Hively, P. C. Gailey, and V. A. Protopopescu, "Sensitive Measures of Condition Change in EEG Data,' Workshop on 'Chaos in Brain?' World Scientific Publ. (pp. 333-336), Bonn, Germany, March 1999.

9. P. C. Gailey, L. M. Hively, and V. A. Protopopescu, "Robust Detection of Dynamical Change in EEG," in proceedings of $5^{\text {th }}$ Experimental Chaos Conference, Orlando, Florida, June 28-July 1, 1999.

10. L. M. Hively, P. C. Gailey, and V. A. Protopopescu, "Detecting Dynamical Change in Nonlinear Time Series," Physics Letters A 258, 103-1 14 (1999).

11. L. M. Hively, V. A. Protopopescu, and P. C. Gailey, Improvements in Condition Assessment of Nonlinear Processes,” U.S. Patent pending ERID-0694, March 7, 2000.

12. L. M. Hively, V. A. Protopopescu, and P. C. Gailey, "Timely Detection of Dynamical Change in Scalp EEG Signals," Chaos 10 (2000) 864-875. 
13. V. A. Protopopescu, L. M. Hively, and P. C. Gailey, "Epileptic Event Forewarning from Scalp EEG," J. Clin. Neurophysiol. 18 (May 2001) 223-245.

14. CRADA \#99-0559, "Epileptic Seizure Prediction by Nonlinear Techniques," between Lockheed Martin Energy Research Corporation and Nicolet Biomedical, Inc. (amended 12/00, 6/0 1 and 7/0 1).

15. L. M. Hively, N. E. Clapp, V. A. Protopopescu, J. Joseph, C. E. Merican, and T. Lucht, Epileptic Seizure Forewarning by Nonlinear Techniques, ORNL/TM-2000/333 (November 2000).

16. L. M. Hively, "Further Improvements for Detection of Nonlinear Condition Change," UT-Battelle Invention Disclosure, October 12, 2000.

17. D. Fish, "Anticipation of Epileptic Seizures from Standard Electra-encephalographic Recordings," The Lancet 357 (1/20/0 1) 160-1 61. 

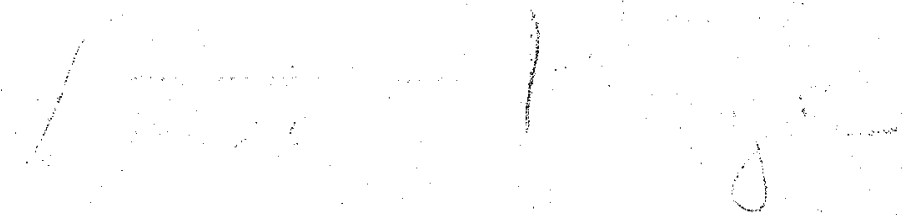

$+$ 


\section{APPENDIX A: TASKS FROM DECEMBER 2000 EXTENSION OF CRADA}

The Participant will perform work under its own internal support. The Contractor will perform activities that are funded primarily by the Participant and, to a lesser degree, by the Department of Energy (DOE) under this CRADA. The original CRADA had a duration of 15 months beginning October 1, 1999, and ending on December 3 1, 2000. The revised CRADA has a duration of 21 months beginning October 1, 1999, and ending on or about June 30, 2001. Work under the revised CRADA will be performed in one phase spanning 21 months (a 6-month extension of the original work) and will focus on development and refinement of a clinical prototype to forewarn an impending epileptic seizure. If the results of this work are successful, the scope of the project may be expanded depending on the needs of the Participant and subject to the availability of additional funding. The first phase consists of three overlapping tasks in which both the Contractor and Participant will have a part. This Addendum only revises Tasks 1.1-1.3, as described below, recognizing that Tasks 2-3 of the original CRADA were completed June 30, 2000.

\section{TASK 1.1 PROVIDE EEG DATASETS (PARTICIPANT)}

The Participant will provide at least 50 additional multichannel EEG datasets in zipped ASCII format to the Contractor. Ideally, these "homogeneous" datasets will be of one seizure type and will typically span an $8 \mathrm{~h}$ monitoring period, beginning with at least 20 min of waking time and ending with an epileptic seizure during the last hour. Practically, we will need at least $1 \mathrm{~h}$ at the beginning of the dataset before the seizure. The Participant will also provide at least 25 datasets for normal (nonepileptic) patients, typically spanning $8 \mathrm{~h}$, including both waking and sleeping periods (not necessarily in the same dataset). If possible, the Contractor would like the Participant to include a $15-\mathrm{Hz}$ sine wave on one of the non-EEG data channels to verify that the data have no gaps and that the sampling frequency is constant in future data. The Participant will provide these normal and "homogeneous" datasets not later than the 16th month (January 2001) of the CRADA period. These datasets are needed to test the hypotheses under Task 1.3, Tests of broader hypotheses will require more data from patients with other types of epilepsy. The Participant will also develop a database for interpretation of the data, including time annotations of preseizure activities, seizure type and occurrence time, recommended EEG channel for analysis, and basic patient information (sex, age). The goal of this task is sufficient statistical data to validate the effectiveness of the forewarning technology for one specific type of epilepsy (such as a partial seizure). The database development also includes the, analysis results from Task 1.2. This task will span the entire 21 -month CRADA period.

\section{TASK 1.2 ·ANALYZE EEG DATA (CONTRACTOR)}

The Contractor will retain at least one archival copy of the data from Task 1.1 on writable CD-ROM. The Contractor will analyze the data using Contractor-patented nonlinear methods for preseizure indications, including a verification of adequate data quality. The Contractor and Participant will assess the results of this analysis in the light of the clinical characterizations, formulate subsequent analysis accordingly, and include the results in the database developed under Task 1.1. This task will span the entire 21-month period of the CRADA.

\section{TASK 1.3 IMPROVE THE WARNING ALGORITHM (CONTRACTOR)}

The Contractor and Participant will assess the performance of the forewarning algorithm based on the results of Task 1.2 in terms of false positives, false negatives, and seizure forewarning times by EEG 
channel. Presently, the nonlinear approach to epilepsy forewarning is based on the following incomplete set of assumptions, which are listed in roughly decreasing order of their generality.

(i) The brain behaves in many respects as a finite-dimensional nonlinear dynamical system under a broad spectrum of circumstances including epilepsy;

(ii) Time-serial EEG data captures the main features of nonlinear brain dynamics;

(iii) The first two assumptions permit the use of methods and measures for nonlinear dynamics and chaos. In particular, PS analysis of time serial EEG data is more sensitive than traditional nonlinear measures for capturing changes in the underlying dynamics from limited sets of noisy data;

(iv) The specific choice of the PS parameters is adequate for epilepsy forewarning;

(v) No correlation exists between the basecase and the seizure, and thus no time relationship between the physiological state of the basecase and seizure;

(vi) The choice of a fixed threshold value for all the data sets is sufficient for forewarning;

(vii) The choice of two successive threshold crossings is necessary and/or sufficient for a forewarning indication;

(viii) Two simultaneous indications from the four dissimilarity measures give a reliable forewarning;

(ix) The same EEG channels consistently provide forewarning for one (or perhaps any) type of epilepsy; and

(x) Normal EEG data gives no false positives.

The validity of assumptions (i) and (ii) is well documented in the technical literature, providing the framework for ongoing studies in the international neuroscience and biomedical community and, therefore, will not be retested under this CRADA effort. Recent peer-reviewed papers by ORNL have demonstrated the clear superiority of the PS method on EEG and model data, so assumption (iii) will not be retested.

The Contractor and Participant (Parties) will analyze the normal and "homogeneous" datasets from Task 1.1 to test the validity of the assumptions (iv)-(x) systematically, including clinical constraints in the algorithm development. These tests will use standard scientific protocols, which include (a) the Occam's razor (rule out a simple approach before constructing a complicated one), (b) rejection of unfalsifiable hypotheses, and (c) acceptance of operationally realizable tests only. In particular, the Parties will test these (and possibly additional) hypotheses one by one, starting with the simplest one via appropriate analysis of the data while keeping the others unchanged. If an assumption is found to be false, then the Parties will determine a more appropriate assumption and test its validity in the same fashion. This effort will include analysis of multichannel data for insights into brain dynamics and epilepsy. The Contractor will revise and test the forewarning algorithm, updating the clinical versions of the code as, appropriate. This task will span the entire 21 -month period of the CRADA.

To date, the algorithm has been tested only on data from epileptic patients, due to the lack of normal (nonepileptic) data. The Parties will test assumption (x) by analysis of (at least) 25 normal data sets of standard length $(8 \mathrm{~h})$. Assumption (x) is valid if the number of false positive indications of condition change is zero. Elimination of any false positives might involve adjustment of the threshold, which now is set arbitrarily.

A test of assumption (ix) will use (at least) 50 "homogeneous" datasets for one type of epilepsy (not yet specified) with a nominal length $(8 \mathrm{~h})$. This analysis will determine which channel(s) consistently give the best forewarning indications for multiple datasets from the same patient. This experimental design will allow a response to objections by Dr. Thomas Cook (biostatistician at the University of 
Wisconsin, Madison) that one or a few EEG channels should, but do not, provide consistent seizure forewarning using our method. Additional data sets will be used to test assumption (ix) for other epilepsy types. This analysis also will serve to clarify assumptions (vi)-(viii).

Tests by the Parties to date have shown that assumption (v) is invalid because different basecase periods from the same dataset give different forewarning indications in various channels. Resolution will require more algorithm development, perhaps involving dissimilarity comparisons of inter-channel PS distribution functions to measure neural synchrony. This analysis is necessary to completely clarify assumption (ix) as well.

A test of assumption (iv) requires statistically significant amounts of standard length data of verified quality for all types of epilepsy together with data from normal (nonepileptic) people. The results of such an analysis would allow a test of universal values for the parameters under assumptions (v)-(x). Such analysis is beyond the scope of the present CRADA effort.

\section{INTERIM MILESTONE}

The Participant wants the Contractor to demonstrate statistically relevant results by March 3 1, 2001, as an interim milestone in Phase $\mathrm{lb}$ of the work. Consequently, the Contractor will seek to validate or invalidate the following null statistical hypothesis: the PS method can provide statistically meaningful forewarning of a temporal-lobe epileptic seizure. Here, statistically meaningful means that the data sample is sufficiently large to allow reasonable use of statistical measures, and that in these data only one variable/hypothesis is tested at a time. Tests of additional hypotheses add more dimensions to the sample space, requiring a suitably increased sample. By mutual agreement, the sample for initial testing has been fixed at 50 datasets. The Participant has already provided 50 temporal lobe EEG datasets to the Contractor for nonblind'analysis. A check of these datasets will be performed to insure adequate length, integrity, and overall data quality. In the case that datasets are rejected due to inadequate quality, the Participant agrees to provide additional replacement datasets. We will test the above hypotheses one at a time. First, we will test the distribution of the forewarning times. We expect that the distribution will be localized within a reasonable, time before the seizure, say $1 \mathrm{~h}$, if the algorithm provides statistically meaningful forewarning. If the time interval between the beginning of the data and the seizure is substantially larger than $1 \mathrm{~h}$, and if forewarning times are randomly distributed over this large time interval, then we would have to conclude that the null statistical hypothesis is invalidated. Second, we will test the algorithm for consistent forewarning in one or a few EEG channels. The analysis of the initial 50 data sets will give an indication on whether this is indeed the case. Furthermore, normal EEG data (controls) should show no forewarning. In order to invalidate/validate this hypothesis,. the participant will provide at least ten normal data sets. The difficulty in obtaining normal data in a timely fashion results in this much smaller sample of normal datasets. Within this constraint, the Parties agree that the statistical significance may be marred by large fluctuations that are associated with such a small sample. 


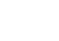




\section{APPENDIX B: TASKS FROM JULY 2001 EXTENSION OF CRADA}

The Participant will perform work under its own internal support. The Contractor will perform activities that are funded primarily by the Participant under this CRADA. The original CRADA had a duration of 15 months, beginning October 1, 1999, and ending December 3 1, 2000. A second revision (App. A) had a total duration of 21 months, beginning October 1, 1999, and ending on or about June 30, 2001. A third revision was a no-cost extension of the CRADA period by one month to July 31,2001 . The present revision extends the CRADA period by 17 months to December 31, 2002, with an additional $\$ 250 \mathrm{~K}$ of funds-in from the Participant. Work under the revised CRADA will focus on development and refinement of a clinical prototype to forewarn of an impending epileptic seizure. If the results of this work are successful, the scope of the project may be expanded, depending on the needs of the Participant and subject to the availability of additional funding. These new tasks (below) recognize that Tasks 1-3 of the original CRADA agreement were completed March 3 1,200 1.

\section{TASK 4.1 COLLABORATE WITH EXPERTS ON EEG/EPILEPSY FOREWARNING (CONTRACTOR AND PARTICIPANT)}

The Participant's goal is a commercial clinical device, followed by an ambulatory device. An essential component toward this goal is input from the physicians. Dr. Joseph's concern is that the Participant's clinical collaborators have stopped providing data for this project, and that he does not expect any more data from them. As Dr. Joseph suggests, ORNL also will seek data and input from international experts in the EEG/epilepsy research. Dr. Brian Litt, M.D. (University of Pennsylvania) is willing to work with ORNL in this regard. Specifically, Dr. Litt is pursuing construction of an EEG database to foster epilepsy prediction research under NIH sponsorship, so sharing of data is certainly possible. Moreover, Dr. Litt is organizing a workshop among the principal international researchers including Christian Elger and Klaus Lehnertz in Bonn, Jacques Martinerie and Michel Le Van Quyen in Paris, J. Chris Sackellares at the University of Florida, and Steven Schiff at George Washington University. Dr. Litt will supply long EEG datasets to each group who can present their results at the workshop. The first desired result of these interactions is additional EEG datasets for analysis under Tasks 4.2, 4.5, and 4.7, in exchange for copies of the EEG data from VIASYS. The second desired result is input on measures of success, the clinical interpretation of inconsistencies (as noted above), potential flaws in the ORNL approach, most appropriate types of data (scalp, subdural, cortical, depth, single vs multiple, type of epilepsy), data features, and analyses to capture these features. The third desired result is input to and participation in research proposals on forewarning of epilepsy via EEG analysis. ORNL will pursue these dialogues via phone, e-mail, teleconferences, meetings, etc. The intent of this task is ongoing input from as many of the international-class experts as possible. ORNL will consult with VIASYS on how to best perform the other tasks, based on the results of this task. This task will span the remainder of the CRADA period.

\section{TASK 4.2 RESOLVE CHANNEL INCONSISTENCY (CONTRACTOR AND PARTICIPANT)}

ORNL will seek to resolve channel inconsistency across multiple datasets from the same patient. VIASYS has provided EEG data that include multiple datasets from 11 patients. This number is not sufficient to obtain good channel-overlap statistics; more data is essential for good statistics. Moreover, data for this analysis must be representative of typical monitoring conditions. Namely, patient EEG is continuously acquired for one week (or more), including several events that the physician examines in detail for diagnosis. We will work with clinical collaborators (Task 4.1) to obtain at least one week of continuous EEG (broken into 21 contiguous and sequential $8 \mathrm{~h}$ datasets for archival purposes) for each of at least 50 patients. These data will be "homogenous," that is for one type of epilepsy, such as temporal lobe. ORNL will analyze each patient's data to determine the best set of PS threshold parameters to 
maximize the sum of true positives (forewarning of confirmed events) and true negatives (no indication during non-event segments). The analysis will seek at least one consistent channel that shows both true positives and true negatives for all of the datasets from the same patient. The goal is all true positives and true negatives for each of the 50 (or more) patients. If this task is successful in combination with Task 4.3, then demonstration of channel consistency with the "active lead" (Task 4.4) will not be needed. ORNL will consult with VIASYS on how to best perform the other tasks, based on the results of this task. This task will span the remainder of the CRADA period.

\section{TASK 4.3 IMPROVEMENTS TO PROVIDE FOREWARNING OF MULTIPLE EVENTS (CONTRACTOR AND PARTICIPANT)}

ORNL will seek consistent forewarning, as described in Task 4.2, for all events in multiple-event datasets. Currently, the ORNL method simply provides forewarning of the first event. This task requires substantial extension of the method to give the following robust indication sequence:

- a true negative (no indication more than $1 \mathrm{~h}$ before the event),

- a true positive (event forewarning within $1 \mathrm{~h}$ of the event),

- indication of the epileptic event (not consistently indicated with the present methodology),

- resetting the forewarning indication to a true negative after this event and before the next event.

Forewarning of multiple events involves a balance between distinguishing closely spaced events and the amount of forewarning time for each event. The goal is forewarning of all multiple events. As suggested by Dr. Joseph, this task will include an alternate approach, namely beginning at the seizure and going backward in time, which is equivalent to using the seizure as the basecase for subsequent comparisons to the other data segments. If this task is successful in combination with Task 4.2, then demonstration of channel consistency with the "active lead" (Task 4.4) will not be needed. ORNL will consult with VIASYS on how to best perform the other tasks, based on the results of this task. This task will span the remainder of the CRADA period.

\section{TASK 4.4 IMPROVEMENTS TO PROVIDE FOREWARNING IN ACTIVE LEAD (CONTRACTOR AND PARTICIPANT)}

ORNL will seek forewarning via the clinically designated "active lead," corresponding to the EEG channel with the first clinical indication of the event. This task will develop and apply nonlinear measures of correlation (synchrony or recruitment) between the "active lead" and composite forms of other channels for event forewarning, because the hallmark of an epileptic event is synchrony between the "active lead" and other channels. This task is contingent on characterization of the "active lead" in each of the datasets, of which VIASYS supplied designations on April 2, 2001, for only 27, Thus, VIASYS will support this task by providing the characterization of the clinically "active lead" for each of the EEG datasets. The desired result from this work is synchrony or correlation measures that forewarn of epileptic events. ORNL will consult with VIASYS on how to best perform the other tasks, based on the results of this task. This task will span the remainder of the CRADA period.

\section{TASK 4.5 DEMONSTRATE EVENT FOREWARNING FOR INTERCRANIAL EEG (CONTRACTOR AND PARTICIPANT)}

The work to date has analyzed scalp EEG only. However, the above inadequacies may arise from inappropriate data. Consequently, ORNL will apply the same analysis as in Tasks 4.2-4.4 on homogeneous data (e.g., temporal lobe epilepsy) from subdural, cranial, and/or depth electrodes. As Dr. Joseph suggests, ORNL will collaborate with other researchers (Task 1) to obtain such data, because 
none of the Participant's clinical collaborators perform depth monitoring. The goal is at least 50 sets of homogenous data to ORNL for this analysis. This task will entail providing the Participant's scalp EEG data to those international groups in exchange for their data. Dr. Joseph agrees that ORNL can share the Participant's data as non-proprietary. As noted under Task 1, Dr. Brian Litt is pursuing construction of an EEG database (scalp and subdural) to foster EEG/epilepsy forewarning research, so the availability of such data is not a problem. ORNL will consult with VIASYS on how to best perform the other tasks, based on the results of this task. This task will span the remainder of the CRADA period.

\section{TASK 4.6 DEVELOP ADVANCED FOREWARNING APPROACHES (CONTRACTOR AND PARTICIPANT)}

ORNL will develop and apply additional methodologies to enhance the discriminating power of the nonlinear measures. Techniques under this development task include the following:

- an empirical mode decomposition (EMD) filter that adaptively changes time scale for artifact removal;

- measures of inter-channel synchrony between lagged PS points for Task 4;

- choice of the best the lag between PS symbols for the connected PS measures, as motivated by the observation of $\mathrm{L}$ and $\mathrm{L}_{\mathrm{c}}$ having the same time variation (as well as $\chi^{2}$ and $\chi_{c}{ }^{2}$ ), meaning that the present choice of lag (one time step now) produces minimal variation between PS points;

- search methodology to find the best choice of PS and threshold parameters as discussed above;

- bipolar vs monopolar EEG;

- equiprobable vs uniform symbols in converting the EEG to PS symbols;

- multiple thresholds for event forewarning;

- forewarning that is based on the "area" above threshold, rather than successive values above threshold.

The goal is to develop advanced analytical methods for epilepsy forewarning. This task is independent of and complementary to the above tasks, constrained only by the number of well-characterized datasets (presently 61, as provided by VIASYS). ORNL will consult with VIASYS on how to best perform the other tasks, based on the results of this task. This task will span the remainder of the CRADA period.

\section{TASK 4.7 SEEK ADDITIONAL SPONSORS FOR THIS WORK (CONTRACTOR AND PARTICIPANT)}

ORNL will seek to alleviate Participant's financial burden for this on-going CRADA collaboration by jointly formulating and submitting proposals for additional funding. Potential sponsors include:

- National Institute of Mental Health;

- DOE's Laboratory Technology Research program;

- Small Business Innovation Research (SBIR) and Small Business Technology Transfer Research (STTR) proposals to NIH;

- A consortium of EEG/epilepsy end-users;

- The TenneeSeed Fund venture capital;

- International Assessment Office (a German company that contacted ORNL about this technology).

VIASYS (or a subsidiary) must satisfy federal criteria for a small business for the SBIR and STTR proposals. VIASYS is reluctant to pursue the last three items so that its present investment in the ORNL technology is not diluted. The goal of this task is federal funding for the CRADA effort after December 3 1, 2002. ORNL will consult with VIASYS on how to best perform the other tasks, based on the results of this task. This task will span the remainder of the CRADA period. 



\section{APPENDIX C: CHARACTERIZATION OF 'TEMPORAL LOBE EPILEPSY DATASETS}

\begin{tabular}{|c|c|c|c|c|c|c|c|c|c|c|c|c|}
\hline PID & DID & $\underline{\mathrm{S}}$ & $\underline{\mathrm{AG}}$ & $\underline{\text { START }}$ & ETEV) & & & & $\underline{\mathrm{AE}}$ & TYP & $\underline{\mathrm{B}-\mathrm{ACT}}$ & $\mathrm{E}-\mathrm{ACT}$ \\
\hline 3 & $\overline{12}$ & $\overline{\mathrm{F}}$ & $\overline{15}$ & $\overline{23: 30}$ & $03: 54$ & $03: 24$ & & & & $\bar{P}$ & & \\
\hline 4 & 13 & $\mathrm{~F}$ & 44 & $07: 56$ & $11: 58$ & $11: 28$ & & & & $\mathrm{P}$ & oOC eatina & reading \\
\hline 5 & 16 & M & 7 & $03: 54$ & $08: 50$ & $08: 20$ & & & & $\mathrm{P}$ & asleep & LIB TV eating \\
\hline 99 & 17 & $\mathrm{~F}$ & 17 & $12: 22$ & $14: 20$ & & & & & $\mathrm{NE}$ & awake & \\
\hline 6 & 18 & $\mathrm{M}$ & 43 & $10: 39$ & $13: 57$ & $13: 26$ & & & & G & Nvov & asleep \\
\hline 6 & 19 & M & 43 & $16: 34$ & $20: 40$ & $20: 10$ & & & & G & asleep & asleep \\
\hline 7 & 20 & $\mathrm{~F}$ & 12 & $19: 40$ & $23: 18$ & $22: 48$ & & & T3 & $\mathrm{P}$ & eating talking & asleep \\
\hline 100 & 22 & $M$ & 21 & $11: 45$ & $13: 50$ & & & & & $\mathrm{NE}$ & awake & \\
\hline 8 & 24 & $\mathrm{M}$ & 30 & $21: 24$ & $01: 09$ & $00: 39$ & & & & P2G & LIB talking & EC LIB talking \\
\hline 8 & 26 & $M$ & 30 & $03: 13$ & $06: 25$ & $06: 55$ & & & & NS & seizure asleep & asleep \\
\hline 11 & 37 & $\mathrm{~F}$ & 42 & $19: 29$ & $01: 18$ & $01: 29$ & & & & NS & & LIB (lights \\
\hline \multicolumn{13}{|l|}{ off) } \\
\hline 11 & 39 & $\mathrm{~F}$ & 42 & $15: 16$ & $20: 18$ & $19: 48$ & & & & $\mathrm{P}$ & asleep TV & LIB FIDG \\
\hline \multicolumn{13}{|c|}{ reading } \\
\hline 12 & 42 & M & 34 & $04: 55$ & $09: 17$ & $08: 47$ & & & & $\mathrm{P}$ & asleep awake NVOV & eating talking \\
\hline 12 & 46 & M & 34 & $10: 23$ & $14: 03$ & $13: 33$ & & & & $\mathrm{P}$ & talking TV LIB & talking SIB \\
\hline 11 & 125 & $\mathrm{~F}$ & 42 & $14: 17$ & $19: 56$ & $19: 13$ & $19: 25$ & & & P2G & TV talking & GU NVOV FIDG \\
\hline 19 & 127 & $\mathrm{M}$ & 4 & $01: 04$ & $04: 49$ & $04: 10$ & & & T3 & NS & asleep & awake SIB LIB \\
\hline 19 & 129 & $\mathrm{M}$ & 4 & $14: 37$ & $17: 59$ & $15: 22$ & $16: 25$ & $17: 29$ & T3 & P2G & asleep & reading talking \\
\hline 11 & 131 & $\mathrm{~F}$ & 42 & $14: 08$ & $19: 30$ & $19: 01$ & & & & $\mathrm{P}$ & SIB TV & TV LOM \\
\hline 22 & 149 & $\mathrm{~F}$ & 43 & $07: 22$ & $09: 12$ & $08: 22$ & & & & $\mathrm{NE}$ & & \\
\hline 22 & 150 & $\mathrm{~F}$ & 43 & $09: 51$ & $11: 52$ & $11: 24$ & & & & $\mathrm{NE}$ & & \\
\hline 24 & 157 & $\mathrm{~F}$ & 41 & $02: 23$ & $04: 24$ & $03: 36$ & & & & $\mathrm{NE}$ & & \\
\hline 24 & 158 & $\mathrm{~F}$ & 41 & $21: 44$ & $23: 36$ & $23: 09$ & & & & $\mathrm{NE}$ & & \\
\hline 24 & 163 & $\mathrm{~F}$ & 41 & $18: 12$ & $19: 36$ & & & & & NS & & \\
\hline 24 & 165 & $\mathrm{~F}$ & 41 & $12: 36$ & $15: 59$ & & & & & NS & & \\
\hline 27 & 170 & $\mathrm{M}$ & 37 & $11: 05$ & $14: 04$ & $14: 02$ & & & F7 & $\mathrm{P}$ & & \\
\hline 75 & 193 & M & 41 & $09: 41$ & $12: 45$ & $12: 39$ & & & T3 & $\mathrm{P}$ & & \\
\hline 81 & 199 & M & 41 & $00: 36$ & $06: 53$ & $06: 45$ & & & T3 & $\mathrm{P}$ & asleep & GU NVOV FIDG \\
\hline 82 & 200 & $\mathrm{M}$ & 23 & $16: 12$ & $20: 40$ & $19: 59$ & & & F3 F4 & G & SIB PWAT & SIB PWAT SPAC \\
\hline 84 & 203 & $\mathrm{~F}$ & 33 & $00: 0.5$ & $05: 44$ & $05: 42$ & & & T3 & P2G & reading & asleep \\
\hline 83 & 207 & $\mathrm{~F}$ & 33 & $08: 06$ & $15: 17$ & $14: 42$ & & & T3 & $\mathrm{P}$ & reading talking & asleep \\
\hline 86 & 211 & M & 41 & $18: 41$ & $23: 59$ & $23: 52$ & & & T3 & P2G & SIB & asleep \\
\hline 74 & 214 & $\mathrm{~F}$ & 32 & $18: 54$ & $23: 50$ & $23: 45$ & & & T3 & $\mathrm{P}$ & asleep & awake TV \\
\hline 74 & 216 & $\mathrm{~F}$ & 32 & $04: 15$ & $07: 11$ & $06: 59$ & & & T3 & $\mathrm{P}$ & asleep & awake IIB/RA GU \\
\hline 89 & 222 & $\mathrm{~F}$ & 52 & $10: 47$ & $15: 02$ & $13: 23$ & $13: 29$ & $14: 27$ & T3 & $\mathrm{P}$ & WWN & SIB talking BP \\
\hline 90 & 221 & $\mathrm{M}$ & 43 & $16: 03$ & $19: 49$ & $19: 19$ & & & T3 & $\mathrm{P}$ & LIB talking EC & SIB eating \\
\hline 40 & 235 & $\mathrm{~F}$ & 51 & $20: 54$ & $02: 42$ & $02: 33$ & & & T4 & P2G & SIC TV & SIB talking \\
\hline \multicolumn{13}{|c|}{ (SPAC) } \\
\hline 46 & 255 & $\mathrm{~F}$ & 16 & $21: 09$ & $00: 51$ & $00: 49$ & & & T3 & $\mathrm{P}$ & asleep & \\
\hline 47 & 259 & $\mathrm{~F}$ & 43 & $11: 54$ & $14: 47$ & $14: 44$ & & & & $\mathrm{P}$ & LIB talking eating & NVOV LIB/VW \\
\hline 48 & 261 & $\mathrm{~F}$ & 14 & $16: 11$ & $21: 17$ & $21: 02$ & & & & NS & LIB TV & LIB 〈LOM $\rangle$ \\
\hline 61 & 264 & M & 33 & $07: 50$ & $11: 14$ & $11: 09$ & & & T3 & $\mathrm{P}$ & & \\
\hline 61 & 265 & M & 33 & $23: 47$ & $06: 33$ & $06: 29$ & & & T3 & $\mathrm{P}$ & TV eating drinking & asleep \\
\hline 61 & 266 & M & 33 & $07: 45$ & $11: 55$ & $11: 52$ & & & T3 & $\mathrm{P}$ & Nvov & SOSB \\
\hline 61 & 267 & $M$ & 33 & $07: 43$ & $10: 45$ & $10: 38$ & & & T3 & $\mathrm{P}$ & SOSB talking & asleep \\
\hline 62 & 270 & $\mathrm{~F}$ & 27 & $15: 46$ & $17: 23$ & $15: 49$ & & & & $\mathrm{NE}$ & & \\
\hline 61 & 271 & $\mathbf{M}$ & 33 & $07: 45$ & $12: 11$ & $11: 57$ & & & T3 & $\mathrm{P}$ & SIB drinking TV & talking SIB \\
\hline 63 & 273 & $\mathrm{~F}$ & 44 & $07: 44$ & $14: 59$ & $10: 31$ & $11: 04$ & $14: 54$ & & $\mathrm{NE}$ & eating talking & SIC talking \\
\hline \multicolumn{13}{|c|}{ yawning } \\
\hline 64 & 274 & $\mathrm{~F}$ & 56 & $07: 38$ & $09: 04$ & $08: 28$ & & & & $\mathrm{NE}$ & & \\
\hline 64 & 275 & $\mathrm{~F}$ & 56 & $07: 37$ & $13: 00$ & $12: 09$ & & & & $\mathrm{NE}$ & drinking & NVOV \\
\hline 64 & 276 & $\mathrm{~F}$ & 56 & $05: 13$ & $11: 38$ & $11: 45$ & & & & $\mathrm{NE}$ & SOSB rocking & Nvov \\
\hline 67 & 283 & $\mathrm{~F}$ & 20 & $11: 38$ & $15: 07$ & $14: 32$ & & & & $\mathrm{NE}$ & talking & breathing hard \\
\hline 65 & 284 & M & 58 & $07: 51$ & $13: 25$ & $13: 11$ & & & & NS & LIB LOOK (SPAC) & SIB TV \\
\hline 67 & 285 & $\mathrm{~F}$ & 20 & $15: 44$ & $20: 35$ & $19: 46$ & & & & $\mathrm{NE}$ & awake SIB & LIB EC \\
\hline 68 & 286 & $\mathbf{M}$ & 56 & $23: 40$ & $04: 11$ & $03: 32$ & & & T3 & P2G & asleep (LOM) & asleep \\
\hline 66 & 287 & M & 19 & $10: 00$ & $17: 28$ & $12: 47$ & $17: 49$ & & & $\mathrm{P}$ & TV & talking \\
\hline 69 & 289 & $\mathrm{~F}$ & 57 & $16: 38$ & $22: 34$ & $21: 38$ & & & T4 & $\mathrm{P}$ & talking NVOV & asleep \\
\hline 70 & 293 & $\mathrm{~F}$ & 44 & $20: 38$ & $00: 38$ & $00: 31$ & & & & $\mathrm{P}$ & TV talking laughing & LIB writing \\
\hline \multicolumn{13}{|c|}{ CARD } \\
\hline 69 & 299 & $\mathrm{~F}$ & 57 & $23: 56$ & $03: 21$ & $03: 19$ & & & $\mathrm{~T} 4$ & $\mathrm{P}$ & TV EC & asleep \\
\hline 72 & 300 & $\mathrm{~F}$ & 44 & $23: 41$ & $05: 11$ & $04: 51$ & & & T3 & $\mathrm{P}$ & asleep & asleep \\
\hline 94 & 308 & $\mathrm{~F}$ & 15 & $08: 14$ & $11: 56$ & $11: 52$ & & & T4 & $\mathrm{P}$ & & \\
\hline 30 & $\begin{array}{l}386 \\
403\end{array}$ & $\begin{array}{l}\mathrm{F} \\
\mathrm{M}\end{array}$ & $\begin{array}{l}15 \\
12\end{array}$ & $\begin{array}{l}05: 57 \\
02: 56\end{array}$ & $\begin{array}{l}10: 49 \\
08: 02\end{array}$ & $09: 04$ & $09: 57$ & & E7 T3 & $\begin{array}{l}P \\
P\end{array}$ & & \\
\hline 54 & 403 & $\mathbb{M}$ & 12 & $02: 56$ & $08: 02$ & $08: 00$ & & & & $\mathrm{P}$ & & \\
\hline
\end{tabular}




\section{APPENDIX D: CRITERIA FOR EVENT FOREWARNING}

The objective is effective seizure forewarning for FDA approval of a medical device. Physicians will provide the device to their patients as part of a protocol for epilepsy treatment. Thus, forecast effectiveness must meet or exceed some minimum criterion, typically set as a rate of true positives $>30 \%$.

We assume that each patient undergoes seizure monitoring according to standard clinical protocols, usually for a week. This monitoring will provide digital EEG data for retrospective analysis, not unlike the analysis of archival patient EEG for the present analysis. The retrospective analysis determines appropriate channels for epilepsy forewarning, based on consistent forewarning in the desired time window. The appropriate statistics are the number of true positives $(T P)$, true negatives $(T N)$, false positives $(F P)$, and false negatives $(F N)$. The diagram below illustrates how these statistics are defined.

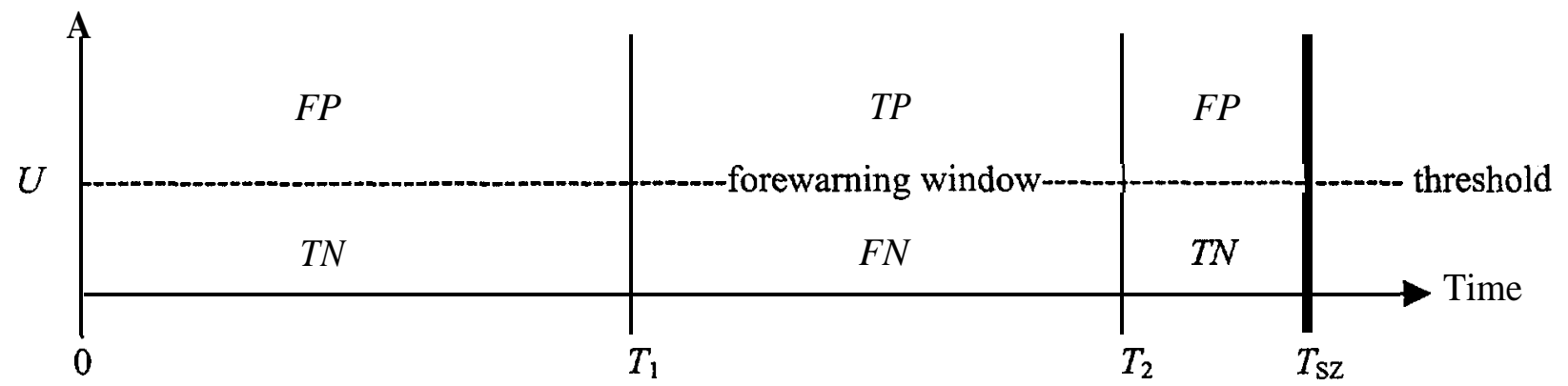

The horizontal axis is time $(t)$. The heavy vertical line at $T_{\mathrm{SZ}}$ denotes the seizure onset time. The light vertical lines delimit the forewarning-time window, $T_{1} \leq t \leq T_{2}<T_{\mathrm{SZ}}$. Clinically useful forewarning requires that $T_{\mathrm{SZ}}-\mathrm{T}_{1} \leq 60 \mathrm{~min}$ and $\mathrm{T}_{\mathrm{Sz}}-\mathrm{T}_{2} \geq 1 \mathrm{~min}$. The vertical axis corresponds to a dissimilarity measure $(U)$. The horizontal dashed line (--) is the threshold for $U$. We define an indication as a number of sequential occurrences $\left(N_{\mathrm{OCC}}\right)$ of $U$ above the threshold. We define a forewarning time $\left(T_{\mathrm{FW}}\right)$ in one channel as the time of a number of simultaneous indications $\left(N_{\text {SIM }}\right)$ among the four dissimilarity measures. The value of $N_{\mathrm{SIM}}=4$ typically provides the best elimination of FPs. Retrospective analysis starts at $t=0$ and proceeds forward in time until the first forewarning occurs, as defined above. The algorithm then obtains the forewarning statistics by an ordered sequence of logical tests for each channel:

$F P=$ Forewarning at any time, when no seizure occurs; or

Forewarning with $T_{\mathrm{FW}}<T_{1}$, or $T_{\mathrm{FW}}>T_{2}$, for a seizure at $t \geq T_{\mathrm{SZ}}$.

$T P=$ Forewarning with $T_{1} \leq T_{\mathrm{FW}} \leq T_{2}$ for a seizure at $t \geq T_{\mathrm{SZ}}$.

$T N=$ No forewarning found, when no seizure occurs.

$F N=$ No forewarning found for $t \leq T_{\mathrm{SZ}}$ with a seizure at $t \geq T_{\mathrm{SZ}}$.

We denote the i-th dataset as a TP $\left(T P_{i}=1\right)$ only if at least one channel has a forewarning in the desired window, $T_{1} \leq T_{\mathrm{FW}} \leq T_{2}$. A TN dataset $\left(T N_{i}=1\right)$ shows no forewarning in at least one channel when no seizure occurs. For a dataset with no TP or TN channels, the FP rate is (number of FP channels)/19 and the FN rate is (number of FN channels)/19, because we analyze 19 EEG channels. We obtain the forewarning statistics by summing the respective rates for all of the datasets and then dividing by the total number of datasets. The total true rate is $T=\Sigma_{i}\left(T P_{i}+T N_{i}\right) /\left(T P_{i}+T N_{i}+F P_{i}+F N_{i}\right)$; the total false rate is $F=\Sigma\left(F P_{i}+F N_{i}\right) /\left(T P_{i}+T N_{i}+F P_{i}+F N_{i}\right)$. This approach allows selection of an appropriate channel for subsequent real-time forewarning, consistent with the retrospective analysis. 



\section{APPENDIX E: SUMMARY OF FOREWARNING ANALYSIS}

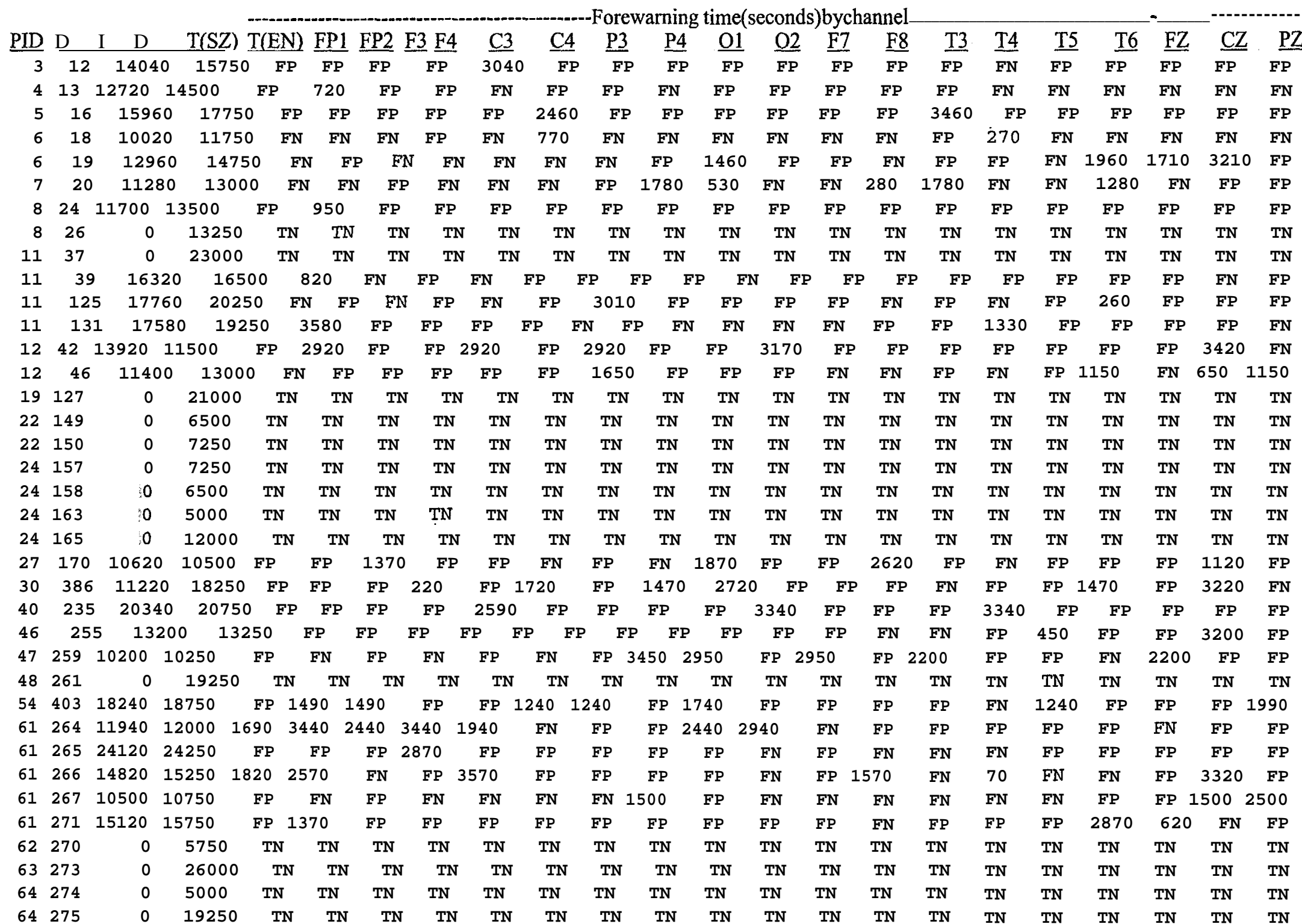


Forewarning time (seconds) by channel -...

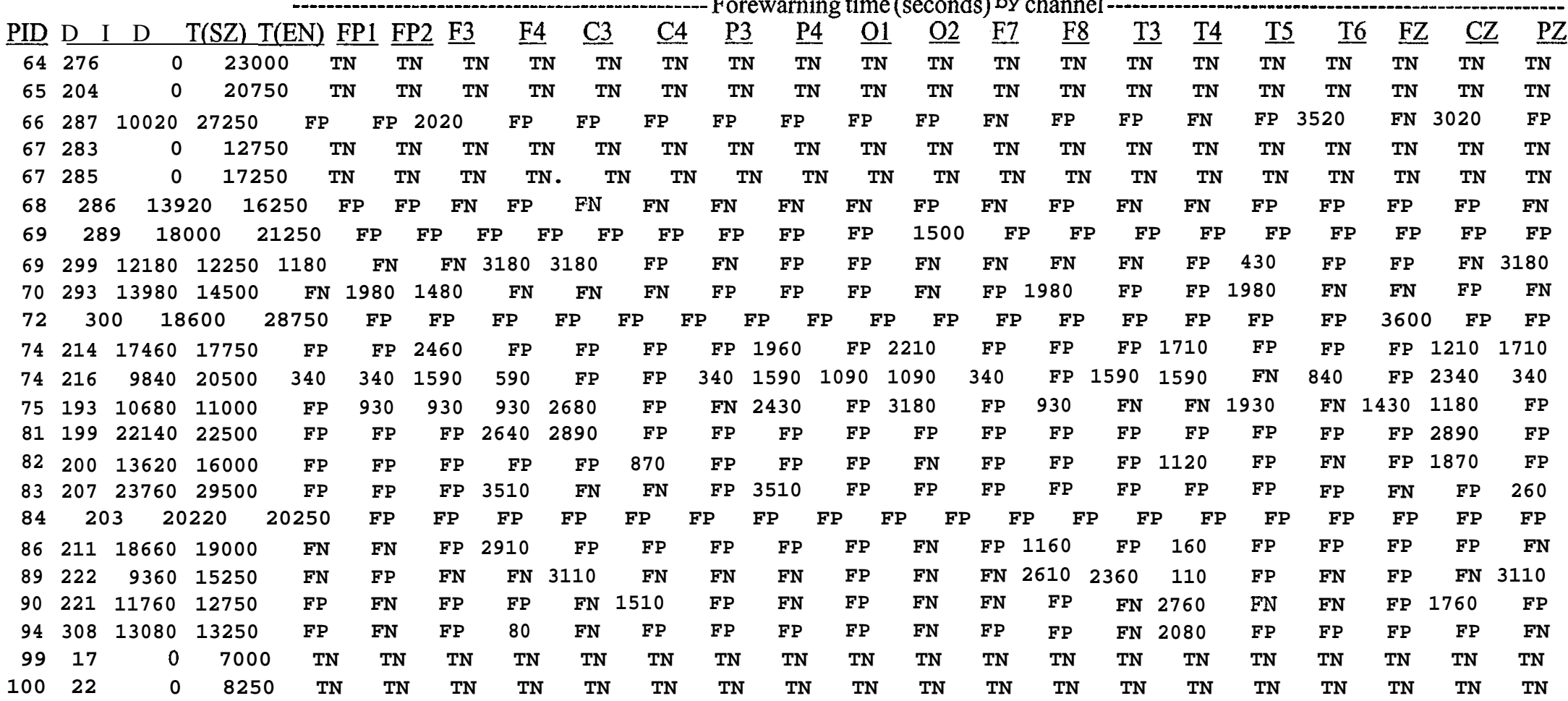

Key: PID = patient identifier, $\mathrm{DID}=$ dataset identifier, $\mathrm{FN}=$ false negative, $\mathrm{FP}=$ false positive, $\mathrm{TN}=$ true negative, $\mathrm{TP}=$ true positive $\mathrm{T}(\mathrm{SZ})=$ time of seizure (seconds) from start of data, $\mathrm{T}(\mathrm{EN})=$ time (seconds) from the beginning to the end of the dataset

0 (under seizure time) $=$ no temporal-lobe-epileptic event

bold PID numbers = multiple datasets for that patient 


\section{APPENDIX F: VALIDATION TESTS OF FORTRAN CODE}

The objective of this testing was threefold. First, we needed to verify improvements to the nonlinear analysis code. Second, we wanted preliminary demonstration that the dissimilarity analysis produces expected and reasonable results for model data. Third, we sought analogous results for EEG data. Details of items two and three are described in ref. 13 and will not be repeated here.

Code improvements (and debugging) have arisen from various tests of new ideas over the second half of 2000. These improvements include equiprobable symbols; Kolmogorov entropy of PS distribution function (DF); routine to search for best PS parameters; routine for mutual information function, based on the same symbols as for the PS reconstruction; read and process basecase data once for construction of basecase PS-DFs and for dissimilarity measures; eliminate divide by zero in normalized Shannon entropy of PS-DF for only one PS bin; analysis of EEG in monopolar or bipolar montage; dissimilarity comparison between channels for same time window; deletion of obsolete routines, variables, and common blocks; and stop the analysis when the next file name is a blank line.

A number of changes eliminated irrelevant error messages or reduced the computational time. Several additions did not provide reasonable results for EEG (Kolmogorov entropy of the PS-DF, interchannel dissimilarity for the same time window). Some new algorithms gave improved results (equiprobable symbols, search for the best PS parameters). We have not tested others adequately (symbolized mutual information function, monopolar vs bipolar analysis). 


\section{APPENDIX G: ANALYSIS TO RESOLVE CHANNEL INCONSISTENCY}

Previous results ${ }^{13}$ for multiple datasets from the same patient did not show consistent forewarning in the same channels, as discussed in the body of this report. Item 4 in Appendix H discusses this issue in the context of all components for an effective epilepsy-forewarning device. Consequently, work under Task 4.2 of the extended CRADA addressed channel consistency, as reported in this Appendix.

Appendixes $\mathrm{C}$ and $\mathrm{E}$ show 11 different patients with multiple datasets: 8 patients with 2 datasets, 1 patient with 3 datasets, 2 patients with 4 datasets, and 1 patient with 5 datasets, involving a total of 30 datasets. We measure channel consistency via the present nonlinear analysis methodology ${ }^{13}$ and forewarning criteria (App. D), as follows:

$i=$ dataset number (DID, dataset identifier in Appendixes $\mathrm{C}$ and $\mathrm{E})$;

$j=$ channel number in which forewarning is determined $(1 \leq \mathrm{j} \leq 19)$;

$k=$ patient number (PID, patient identifier in Appendixes $\mathrm{C}$ and $\mathrm{E}$ );

$M(k) \quad=$ number of datasets for the $\mathrm{k}$-th patient;

$P \quad=$ number of patients with multiple datasets (eleven for the present analysis);

$T N_{i j k}=1$ for a true negative indication in thej-th channel of the i-th dataset for the k-th patient, $=0$ for a false negative indication in the $\mathrm{j}$-th channel of the $\mathrm{i}$-th dataset for the $\mathrm{k}$-th patient;

$T P_{i j k}=1$ for a true positive indication in thej-th channel of the $i$-th dataset for the $k$-th patient, $=0$ for a false positive indication in the $\mathrm{j}$-th channel of the $\mathrm{i}$-th dataset for the $\mathrm{k}$-th patient;

$T_{j k}=\Sigma_{\mathrm{i}}\left[T P_{i j k}+T N_{i j k}\right]$ is the total trues for the $\mathrm{j}$-th channel of the k-th patient, sum over $i=1$ to $M(k)$.

The occurrence of more than one true positive and/or true negative in the $\mathrm{j}$-th channel is indicated by $T_{j k} \geq 2$, while $T_{j k} \leq 1$ means that the $\mathrm{j}$-th channel provides no overlap with other datasets for the same patient. Consequently, we define the channel overlap as:

$$
\begin{aligned}
c_{k} \quad & =\max \left(T_{j k}\right) / M(k), \text { for } T_{j k}>1, \\
& =0, \text { for } T_{j k} \leq 1 .
\end{aligned}
$$

Here, max $\left(T_{j k}\right)$ denotes the maximum value of $T_{j k}$ over all of the possible EEG channels $(j$ index $)$ for each dataset for the k-th patient. The average channel consistency over all of the patients is then $\mathrm{C}=\Sigma_{k} c_{k} / P$, summing over all $\mathrm{P}$ of the patients. Several approaches exist for this optimization:

(1) Maximize $T$ to get $T_{x}$;

(2) Maximize $\mathrm{C}$ to get $C_{x}$;

(3) Maximize $\mathrm{C}+T$ as a hybrid objective function, $(\mathrm{C}+T)_{\mathrm{x}}$;

(4) Maximize $T$, subject to the constraint of $\mathrm{C}>C_{\min }$, for some minimum value, $C_{\min }$;

(5) Maximize $\mathrm{C}$, subject to the constraint of $T>T_{\min }$, for some minimum value, $T_{\min }$.

All of these objective functions are "reasonable" but provide only ad hoc measures. We just formulated a less ad hoc objective function as the CRADA ended and have no definitive results to present. 



\section{APPENDIX H: FUTURE WORK FOR AN AMBULATORY PROTOTYPE}

Much additional work is needed? to convert the present nonlinear technology into a commercial ambulatory medical device for. forewarning of epileptic events. FDA approval of such a device requires a demonstration of effectiveness and safety. Safety issues are beyond the scope of the present work. The following table provides a preliminary“ (and certainly not exhaustive) list of the effectiveness criteria.

For the situation below

1. Epileptic event in one channel of one dataset

2. Dataset without an epileptic event

3. More than $1 \mathrm{~h}$ before an event

4. Several seizure datasets from the same patient

5. Multiple seizures in one dataset

6. Many days of monitoring for one patient

7. Patients of various ages

8. Patients of both sexes

9. Onset time of the event (e.g., day vs night)

10. Pre-event patient activity (e.g., awake vs sleep)

11. Other types of epilepsy

12. Awake- vs sleep-state basecase

13. Loss of data or inadequate data quality

14. Patients under medication

15. Estimate time until the event

\begin{tabular}{|c|c|}
\hline Effective forewarning should be & $\underline{\text { Status }}$ \\
\hline True positive & $\overline{Y^{13}}$ \\
\hline True negative & $Y^{13}$ \\
\hline True negative & $Y^{13}$ \\
\hline True positives in same channel(s) & $\mathrm{N}$ \\
\hline True positive for each event & $\mathrm{N}$ \\
\hline True negative between each event & $\mathrm{N}$ \\
\hline Same as item 5 & $\mathrm{~N}$ \\
\hline Independent of this variable & $Y^{13}$ \\
\hline Independent of this variable & $Y^{13}$ \\
\hline Independent of this variable & $\mathrm{Y}^{13}$ \\
\hline Independent of this variable & $Y^{13}$ \\
\hline Independent of this variable & $\mathbf{N}$ \\
\hline Independent of this variable & $Y^{13}$ \\
\hline Suspended until data is adequate & $Y^{15}$ \\
\hline Same as $1-13$ & $\mathbf{N}$ \\
\hline Same as $1-13$ & $\mathbf{N}$ \\
\hline
\end{tabular}

Best effectiveness is obtained by maximizing the rate of true positives (items $1,4,5,6$ ), plus true negatives (items $2,3,5,6$ ), independent of the other variables (items 7-12). Our analysis ${ }^{13}$ has shown forewarning effectiveness that is independent of patient's age, patient's sex, event onset time, pre-event activity, awake- vs asleep-state basecase, and data quality. However, these results depend rather heavily on optimizing the PS analysis parameters. The "Status" column in this table indicates whether our present analysis has shown that the methodology is already adequate or has the capability to address this component in the near future (Y), or has not yet demonstrated, this aspect $(\mathrm{N})$. Several of these items are $\mathrm{N}$ because we presently do not have the necessary patient EEG data (item 6 and 14) or because existing data has not been characterized for this feature (item 11). Methodology improvements certainly will involve optimization over the threshold parameters (App. D) and perhaps new threshold measures such as the integral over the time spent above threshold.

Our work to date has, focused on event forewarning in any one EEG channel, which is a rather weak indication. All of the above effectiveness criteria . also apply to consistent indication in multiple (preferably most or all) EEG channels to' facilitate "n\&clinical" electrode placement. Application of the above effectiveness criteria to the "active lead" was identified by the Participant as a desirable feature of a commercial. device, for acceptance by physicians. The "active lead" designation corresponds to the EEG channel, in which the physician sees the first clinical indication of the event. However, forewarning in the active lead is not a necessary feature for an effective device.

We note that the forewarning window (nominally chosen between 1-60 min before the event) is based on the maximum and minimum useful times for clinical response to an impending event. Analysis for other forewarning windows (e.g., less than $1 \mathrm{~h}$, and/or more than $1 \mathrm{~min}$ ) is beyond the present effort. Such analysis is pointless without physician input, which we do not have now. 
Various alternatives are possible if later analysis shows that an item influences effectiveness. A new basecase can be acquired every $x$ days (item 6), or when the data quality check detects too much noise or loss of signal (item 13). The algorithm might be tuned by age (item 7), by sex (item 8), or perhaps for each patient. If an awake- vs an asleep-basecase changes the technique's effectiveness (item 12), then an awake-state basecase can be obtained by a straightforward clinical protocol. Namely, the initial patient setup would assure that the patient is awake during the scalp electrode hook-up by medical personnel, who then explain the device and its use to the patient while the basecase is acquired for several minutes. A difficult problem for item 11 is that a seizure follows almost immediately after presentation of a stimulus in some reflex epilepsies. ${ }^{17}$ Solutions to these issues must be tested for effectiveness.

We were in the process of addressing forewarning consistency in the same EEG channels for several seizure datasets from the same patient (Task 4.2 of App. B) when the CRADA work was terminated. Appendix G describes the results to date, which are very encouraging. Present analysis relies on EEG data that include multiple datasets from 11 patients. This number is not sufficient to obtain good channeloverlap statistics; more data is essential for improving the statistics. Moreover, data for this analysis must be representative of typical monitoring conditions. Namely, patient EEG is acquired continuously for one week (or more), including several events that the physician examines in detail for diagnosis. A demonstration of effectiveness for FDA device approval will require at least one week of continuous EEG (broken into contiguous, sequential datasets for archival and analysis purposes) for each of at least 50 patients. These data should be "homogenous," that is for one type of epilepsy, such as temporal lobe. Our analysis then will determine the best set of PS and threshold parameters to maximize the sum of true positives (forewarning of confirmed events) and true negatives (no indication during non-event segments). The analysis will seek at least one consistent channel that shows both true positives and true negatives for all of the datasets from the same patient. The goal is to obtain all true positives and true negatives for each of the 50 patients, using the same set of PS parameters. Items 6 and 11 (effectiveness over many days) also can be addressed by this same analysis.

A second important issue is forewarning for all events in multiple-event datasets. Currently, the PS dissimilarity method simply provides forewarning of the first event. This work will require substantial extension of the method to give the following robust indication sequence:

- a true negative (no indication) more than $1 \mathrm{~h}$ before the event,

- a true positive (event forewarning) within $1 \mathrm{~h}$ of the event,

- indication of the epileptic event (not consistently indicated with the present methodology),

- return of the forewarning indication to a true negative after this event, and before the next event.

Forewarning of multiple events involves a balance between distinguishing closely spaced events, and the amount of forewarning time for each event. The present EEG data (App. C) includes six multi-event datasets: three datasets with two events, and three datasets with three events. Ten datasets is the minimum for any statistical analysis. A demonstration of effectiveness for FDA device approval will require at least 50 datasets. These data should be "homogenous," that is for one type of epilepsy, such as temporal lobe. Our analysis then will determine the best set of PS and threshold parameters to maximize the sum of true positives (forewarning of confirmed events) and true negatives (no indication during non-event segments). Dr. Joseph suggested that this effort include an alternate approach for the basecase, namely beginning at the seizure and going backward in time, which is equivalent to using the seizure as the basecase for subsequent comparisons to the other data segments. The goal is all true positives and true negatives for all multiple events in at least one consistent channel from each of the 50 datasets, preferably from each of 50 different patients. 
A new approach is necessary for forewarning in the "active lead," which typically provides indications that precede the event by much more than $1 \mathrm{hr}$. One alternative is nonlinear measures of correlation (synchrony or recruitment) between the "active lead" and (composite forms of) other channels for event forewarning, because the hallmark of an epileptic event is synchrony between the "active lead" and other channels. Another method is threshold parameters that are much less sensitive to avoid premature forewarning. A third possibility is measures of inter-channel synchrony between lagged PS points. A fourth idea is multiple thresholds for event forewarning. We have observed that pairs of PS dissimilarity measures have the same time variability, meaning that the present choice of inter-symbol lag (one time step now) produces minimal variation between PS points. Hence, a fifth notion is a better choice of the lag between PS symbols for the connected PS measures. Artifact removal may be a hidden problem, for which an empirical mode decomposition filter may help by adapting to the changing artifact time scale. This effort is contingent on characterization of the "active lead" in each of the datasets. We presently have active lead designations for only 27 of the 41 event datasets. The desired result from this work is measures that consistently forewarn of epileptic events in the active lead. This effort will not be needed if the above work succeeds in achieving forewarning for multiple events in the same dataset and for the same EEG channels across multiple datasets from the same patient.

Demonstration of event forewarning for other types of epilepsy will require the same analysis as discussed above, for at least 50 homogeneous EEG datasets for each epilepsy type. [Under Task 4.1, we contacted Dr. Brian Litt, who is pursuing construction of an EEG database (scalp and subdural) to foster EEG/epilepsy forewarning research, so the availability of such data may not be a problem.] Our analyses to date are for data in the monopolar montage. Analysis of data in the bipolar montage involves the difference of signals between adjacent EEG channels and may improve forewarning for other types of epilepsy. A desirable attribute of a commercial forewarning device is an estimate of the time until the impending seizure (item 15), which the present technology is too immature to address. 



\section{INTERNAL DISTRIBUTION}

1. J. Barhen

2. C. S. Daw

3. L. M. Dickens

4. E. C. Fox

5. D. M. Hetrick

6-10. L. M. Hively

11. R. F. Holdaway

12. G. T. Mays

13. T. L. Payne
14-18. V. A. Protopopescu

19. J. C. Wells

20. K. M. Wilson - 0559-RC

21. B. A. Worley

22. T. Zacharia

23. Central Research Library

24. Laboratory Records - RC

25-26. Laboratory Records - for transmittal to OSTI

\section{EXTERNAL DISTRIBUTION}

27. J. Joseph, Director of Technology and Software Quality, VIASYS Healthcare Inc., 5225 Verona Rd., Building \#2, Madison, WI 5371 1-4495.

28. DOE Work For Others Office, MS-G209

29. P. A. Carpenter, Department of Energy, Oak Ridge Operations Office, P.O. Box 2008, Oak Ridge, TN 37831-6269

30. R. E. Price, US. Department of Energy, NE-20, Room E-461, 19901 Germantown Rd., Germantown, MD 20874-1290

31. S. J. Barish, Laboratory Technology Research Program, SC-32, Room E220, 19901 Germantown Rd., Germantown, MD 20874-1290 
